\title{
Correction to: Impact of age on morbidity and mortality following bariatric surgery
}

Sean R. Maloney ${ }^{1} \cdot$ Nicholas Dugan $^{2}$ - Tanushree Prasad ${ }^{1}$ - Paul D. Colavita ${ }^{1} \cdot$ lain H. Mckillop ${ }^{3} \cdot$ Keith S. Gersin $^{1,2}$. Timothy Kuwada ${ }^{1,2} \cdot$ Selwan Barbat ${ }^{2} \cdot$ Amanda Roberts $^{2} \cdot$ Abdelrahman Nimeri $^{1,2}$

Published online: 19 February 2020

๑) Springer Science+Business Media, LLC, part of Springer Nature 2020

\section{Correction to: Surgical Endoscopy} https://doi.org/10.1007/s00464-019-07201-2

This article was updated to correct the spelling of Nicholas Dugan's first name: it is correct as displayed here.

Publisher's Note Springer Nature remains neutral with regard to jurisdictional claims in published maps and institutional affiliations.

The original article can be found online at https://doi.org/10.1007/ s00464-019-07201-2.

Abdelrahman Nimeri

Abdelrahman.Nimeri@atriumhealth.org

1 Division of Gastrointestinal \& Minimally Invasive Surgery, Department of Surgery, Carolinas Medical Center, Charlotte, NC, USA

2 Divison of Bariatric Surgery, Department of Surgery, Carolinas Medical Center, 2630 E. 7th Street, Charlotte, NC 28204, USA

3 Surgical Research, Department of Surgery, Carolinas Medical Center, Charlotte, NC, USA 